\title{
Factors associated with Assisted Partner Notification Services in Seme and Kisumu west sub counties, Kenya.
}

Anangwe Munala Samson ${ }^{1}$, Dennis G. Magu ${ }^{1}$, Fredrick O. Otieno ${ }^{1}$.

${ }^{1}$ Jomo Kenyatta University of Agriculture and Technology.

\begin{abstract}
.
Background: Assisted partner notification service (aPNS) is a public health strategy which entails a health worker interviewing persons identified with an STI (index cases) about their sexual partner(s) and/or contacts and then providing the index case with some level of assistance notifying their partner(s) and assuring their testing. Assisted partner notification services was implemented, as a public health intervention to identify individuals' new HIV infections and facilitate linkage to care.
\end{abstract}

Methods: Participants aged 18 years and above were selected and enrolled in the study through simple random sampling. Participants provided written informed consent to participate in the study. Logistic regression (bivariate and multivariate) analysis was performed on data to determine factors associated with participation in aPNS. Backward stepwise elimination was used to select variables to be included in the multivariate level to estimate the odds ratios (OR).

Results: We enrolled 423 participants of which $62.5 \%$ were aged 18-25 and women $(n=228$, $54.5 \%)$ and men $(n=190,45.5 \%)$. Overall participation in aPNS was $69.1 \%$. The predictors of participation in aPNS were occupation and residence. The odds of participating in aPNS was higher for those who practiced peasantry $(\mathrm{aOR}=2.04$; 95\% CI, 1.08-3.85, $\mathrm{p}=0.029)$. However, those in the urban were less likely to participate in aPNS compared to those in the rural setting notification $(\mathrm{aOR}=0.57 ; 95 \% \mathrm{CI}, 0.33-0.98, \mathrm{p}=0.042)$ and those employed were less likely to participate in aPNS compared to those unemployed $(\mathrm{aOR}=0.56 ; 95 \% \mathrm{CI}, 0.33-0.95, \mathrm{p}=0.032)$.

Conclusion: There is need to target interventions targeting assisted partner notification in the urban settings and among those in the workforce.

Key words: Assisted partner notification services, Prevalence, HIV testing, Linkage, Kenya.

\section{Introduction.}

Globally, identification for HIV through testing is vital and crucial to the control of the HIV epidemic. Despite increased awareness of HIV status and expanded access to antiretroviral 
therapy (ART), estimates indicate that $60 \%$ of HIV infected individuals in sub Saharan Africa are unaware of their status. There is need to increase HIV testing in order to achieve the 95-9595 objectives by 2030 (UNAIDS, 2014). Estimates indicate that one out of four PLHIV globally did not know their HIV status, despite efforts and resources invested towards HIV testing within the UNAIDS 95-95-95 strategy(UNAIDS, 2018). Therefore, to actualize this goal, current HIV testing efforts must be significantly scaled up. A significant breaking point in the treatment cascade remains at the HIV case finding and diagnosis level across many countries. This has led to the implementation of assisted partner notification services (aPNS) as a public health intervention to identify individuals new HIV infections and facilitate linkage to care(Dalal et al., 2017).

Globally, countries such as United States of America (USA), Canada and Singapore came up with laws on aPNS to encourage disclosure of HIV status. Provider aPNS is an important HIV prevention strategy in USA and Europe and encourages testing and disclosure (Hogben, McNally, McPheeters, \& Hutchinson, 2007). In Sub-Saharan Africa partner notification has been shown to be feasible and acceptable (Brown et al., 2011), with Kenya integrating aPNS in the HIV testing services although on voluntary basis.

Some health departments in parts of the USA and Europe developed aPNS program targeting HIV as early as the 1980s, and have demonstrated that aPNS is an effective strategy towards HIV case finding and promotion of safer behaviours (Hogben, McNally, McPheeters, Hutchinson, et al., 2007). Despite the strategy being resource intensive, studies suggest that aPNS can be cost-effective and cost saving because of its HIV prevention potential and the consequent cost of HIV care (Varghese et al., 1999). On the other hand, aPNS entails confidentiality safeguards and intimate partner violence (IPV) screening, and as a result social harms are rarely reported (Hogben, McNally, McPheeters, Hutchinson, et al., 2007).

According to a study on index characteristics of partner notification services, immediate aPNS was more efficacious than delayed aPNS. Further the study indicated that higher rates of partner HIV testing were also observed for index participants in rural/peri-urban compared to urban sites, female compared to male index participants and those who were less than 30 years. Further, findings indicated that provision of the aPNS to female index participants also had a 
significantly higher HIV case finding rate compared to male index participants (Masyuko et al., 2019). There is need to understand factors associated with aPNS in order to scale up the strategy.

\section{Methods.}

\section{Study design.}

The study adopted a descriptive cross sectional research design. The descriptive study design enabled the researcher to gain understanding of the accurate portrayal and/or account of the characteristics of study participants in their real life situations. This was for the purposes of defining and discovering new meaning, describing existing characteristics, determining frequency of occurrence of variables of interest and categorization of information for purposes of analysis.

\section{Study Setting.}

The study site was Seme and Kisumu West sub counties of Kisumu County which is one of the 47 Counties in Kenya. The area of study was selected purposively because the area covers the demographics surveillance area that is in Seme and Kisumu West sub counties.

\section{Recruitment and Data collection.}

To be included, participants had to be; aged above 18 years; attending HIV clinical care in the sampled health facilities; and willing to consent to participate in the study. The three health facilities were randomly selected. They included two public health facilities in Seme Sub County and one in Kisumu West Sub County namely Chulaimbo Sub County Hospital in Kisumu west and Kombewa and Manyuanda Sub county Hospitals in Seme sub county. These facilities accounted for a larger proportion of the clients on care in the two sub counties. Sampling was based on the target population of 9,942 individuals as per the population profile of Seme and Kisumu West Sub Counties. Participants were sampled in a two-step process. Stratified sampling method was used to generate the sample size. The sample size in each health facility was in respect to the size of the population of individuals accessing HIV care and treatment services in the facilities followed by simple random sampling to select participants within each facility yielding a total of 423 participants. Following consenting, interviewer administered structured questionnaires were read out for the participants by the research assistants in the language they best understand- either English or Dholuo. Respondents were informed that participating in the 
study was voluntary and they were free to withdraw their participation should they find that necessary and their decision to withdraw did not influence/affect the HIV referral; care and treatment services that would be offered to them afterwards in any way. Respondents who consented to participate in the study were then requested to complete consent forms to participate in the study. Unique numbers were used to code questionnaires and consent forms to conceal the identity of respondents participating in the study. Confidentiality and dissemination of information was discussed with the respondents prior to administering the questionnaires.

\section{Data Analysis.}

Descriptive statistics was used to characterize the sample. We conducted separate bivariate and multivariate analyses to examine associations between participation of assisted partner notification and demographic characteristics.Logistic regression was used to estimate the odd ratios $(\mathrm{OR})$ and $95 \%$ confidence intervals $(\mathrm{CI})$ in the bivariate and multivariate models. In the first step of model selection, a bivariate model was applied. A selection criterion of $\mathrm{p}$ value less than 0.2 was used to select variables to the multivariate model. A final multivariable model was developed through backward stepwise elimination and retaining predictors significant at $\mathrm{p}<0.05$.Data was analysed using STATA version 14.2.

\section{Measures.}

Outcome Variable: Participants were asked if they participated in assisted partner notification. Those who responded "yes" were coded as having participated and those who responded "no" were coded as not having participated. Other demographic variables include: age, gender, highest education level, marital status, religion and area of residence

\section{Ethics.}

The researcher obtained certificate of ethical approval to conduct this research study from the ethical approval bodies/IRBs- Jaramogi Oginga Odinga Teaching and Referral Hospital (JOOTRH) Ethical Approval Board, Ministry of Health- Kisumu County Director of Health office, Seme and Kisumu West Sub County Medical Officer of Health Offices, Medical Superintendents at Kombewa and Chulaimbo County Hospital and Facility in charge at Manyuanda Sub County Hospital. Written letter of authorization to proceed for data collection 
was obtained from Jomo Kenyatta University of Agriculture and Technology- board of post graduate studies, department of public health; college of health sciences.

Results.

Association between Socio demographic characteristics and assisted partner notification services.

Table 1: Association between socio demographic characteristics and aPNS.

\begin{tabular}{|c|c|c|c|c|}
\hline Variable/Factor & $\operatorname{Total}(\mathrm{N})$ & $\operatorname{No}(\mathrm{n}(\%))$ & $\operatorname{Yes}(\mathrm{n}(\%))$ & $\mathrm{p}$ value \\
\hline aPNS participation & $423(100)$ & $131(30.9)$ & $292(69.1)$ & \\
\hline \multicolumn{5}{|l|}{ Age category } \\
\hline $18-25 \mathrm{yrs}$ & $72(17.1)$ & $27(37.5)$ & $45(62.5)$ & \multirow[t]{4}{*}{0.035} \\
\hline $26-35$ yrs & $141(33.5)$ & $37(26.2)$ & $104(73.8)$ & \\
\hline $36-45$ yrs & $129(30.6)$ & $48(37.2)$ & $81(62.8)$ & \\
\hline Above 45 yrs & $79(18.8)$ & $17(21.5)$ & $62(78.5)$ & \\
\hline \multicolumn{5}{|l|}{ Gender } \\
\hline Male & $190(45.5)$ & $64(33.7)$ & $126(66.3)$ & \multirow[t]{2}{*}{0.15} \\
\hline Female & $228(54.5)$ & $62(27.2)$ & $166(72.8)$ & \\
\hline \multicolumn{5}{|l|}{ Marital status } \\
\hline Single & $70(16.9)$ & $26(37.1)$ & $44(62.9)$ & \multirow[t]{3}{*}{0.512} \\
\hline Married/Cohabiting & 264(63.9) & $79(29.9)$ & $185(70.1)$ & \\
\hline Separated/Divorced/Widowed & $79(19.1)$ & $25(31.6)$ & $54(68.4)$ & \\
\hline \multicolumn{5}{|l|}{ Occupation } \\
\hline Self employed & $167(40.0)$ & $51(30.5)$ & $116(69.5)$ & \multirow[t]{4}{*}{0.001} \\
\hline Employed & $96(23.0)$ & $43(44.8)$ & $53(55.2)$ & \\
\hline Peasant & $97(23.3)$ & $17(17.5)$ & $80(82.5)$ & \\
\hline Unemployed & $57(13.7)$ & $17(29.8)$ & $40(70.2)$ & \\
\hline \multicolumn{5}{|l|}{ Religion } \\
\hline Islam/Traditional/Pagan & $21(5.0)$ & $10(47.6)$ & $11(52.4)$ & \multirow[t]{2}{*}{0.088} \\
\hline Christian & 397(95.0) & $119(30.0)$ & $278(70.0)$ & \\
\hline \multicolumn{5}{|l|}{ Highest level of education } \\
\hline None/Primary level & $225(53.6)$ & $59(26.2)$ & $166(73.8)$ & \multirow[t]{3}{*}{0.032} \\
\hline Secondary level & $124(29.5)$ & $41(33.1)$ & $83(66.9)$ & \\
\hline College/University level & $71(16.9)$ & $30(42.3)$ & $41(57.7)$ & \\
\hline \multicolumn{5}{|l|}{ Residence } \\
\hline Rural & $344(82.1)$ & $96(27.9)$ & $248(72.1)$ & \multirow[t]{2}{*}{0.003} \\
\hline Urban & $75(17.9)$ & $34(45.3)$ & $41(54.7)$ & \\
\hline
\end{tabular}

Table 1: Socio-demographic characteristics of the participants.

A total number of 423 adults on HIV care participated in the study and majority (33.5\%) aged between $26-35$ years and $54.5 \%$ of them were female while married were $(63.4 \%)$ and Christians 
(95\%). Majority of the respondents in the study resided in the rural setting (82.1\%) and most of them were self-employed (40\%). Moreover, 53.5\% of subjects attained primary level education. Out of the total number of participants, $69.1 \%$ of them participated in assisted participated in assisted partner notification.A comparison of socio-demographic characteristics between those who reported participation in aPNS and those who did not participate indicated that . ,out of the total number of participants, $62.5 \%$ of those aged $18-25$ participated in aPNS while $78.5 \%$ of those who were aged above 45 years engaged in aPNS. In terms of occupation, $82.5 \%$ of those who were peasants engaged in aPNS, while $55.2 \%$ of those who were employed participated in aPNS. Further, majority of those who participated in aPNS had none or primary level education $(73.8 \%)$ and resided in the rural setting $(72.1 \%)$.

Table 2: Bivariate and multivariate analysis.

\begin{tabular}{|c|c|c|c|c|c|c|}
\hline Variable/Factor & $\begin{array}{l}\text { unadjusted } \\
\text { OR }\end{array}$ & $95 \% \mathrm{CI}$ & $\begin{array}{l}\mathbf{p} \\
\text { value }\end{array}$ & $\begin{array}{l}\text { adjusted } \\
\text { OR }\end{array}$ & $95 \% \mathrm{CI}$ & $\begin{array}{l}p \\
\text { value }\end{array}$ \\
\hline \multicolumn{7}{|l|}{ Age category } \\
\hline Above 45 yrs & 1 & & & & & \\
\hline $18-25$ yrs & 0.46 & $0.22-0.94$ & $* 0.033$ & & & \\
\hline $26-35$ yrs & 0.77 & $0.40-1.48$ & 0.436 & & & \\
\hline $36-45$ yrs & 0.46 & $0.24-0.88$ & $* 0.019$ & & & \\
\hline \multicolumn{7}{|l|}{ Gender } \\
\hline Male & 1 & & . & & & \\
\hline Female & 1.36 & $0.89-2.07$ & 0.15 & & & \\
\hline \multicolumn{7}{|l|}{ Marital status } \\
\hline Single & 1 & & & & & \\
\hline Married/Cohabiting & 1.38 & $0.80-2.40$ & 0.249 & & & \\
\hline \multicolumn{6}{|l|}{ Occupation } & \\
\hline Self employed & 1 & & & 1 & & \\
\hline Employed & 0.54 & $0.32-0.91$ & $* 0.021$ & 0.56 & $0.33-0.95$ & 0.032 \\
\hline Peasant & 2.07 & $1.11-3.84$ & $* 0.021$ & 2.04 & $1.08-3.85$ & 0.029 \\
\hline Unemployed & 1.03 & $0.54-1.99$ & 0.919 & 0.97 & $0.50-1.89$ & 0.937 \\
\hline \multicolumn{7}{|l|}{ Religion } \\
\hline Islam/Traditional/Pagan & 1 & & . & & & \\
\hline Christian & 2.12 & $0.88-5.13$ & 0.095 & & & \\
\hline \multicolumn{7}{|l|}{ Highest level of education } \\
\hline None/Primary level & 1 & & & & & \\
\hline Secondary level & 0.72 & $0.45-1.16$ & 0.177 & & & \\
\hline College/University level & 0.49 & $0.28-0.85$ & $* 0.011$ & & & \\
\hline \multicolumn{7}{|l|}{ Residence } \\
\hline Rural & 1 & & . & 1 & & . \\
\hline Urban & 0.47 & $0.28-0.78$ & $* 0.004$ & 0.57 & $0.33-0.98$ & 0.042 \\
\hline
\end{tabular}


Bivariate logistic regression indicated that participants aged 18 -25 years were 54\% less likely to participate in aPNS compared to those aged above 45 years (OR=0.46; 95\% CI, 0.22-0.94; $\mathrm{p}=0.033 *)$. Respondents who were employed were $46 \%$ less likely to participate in aPNS compared to those who were self-employed ( $\mathrm{OR}=0.54 ; 95 \% \mathrm{CI}, 0.32-0.91, \mathrm{p}=0.021 *$ ) while those who were peasants were 2 times more likely to participate in aPNS compared to those who were self-employed $\left(\left(\mathrm{OR}=2.07 ; 95 \% \mathrm{CI}, 1.11-3.84, \mathrm{p}=0.021^{*}\right)\right.$. Moreover, those with college and university were $51 \%$ less likely to participate in aPNS compared to those with no education. $(\mathrm{OR}=0.49 ; 95 \% \mathrm{CI}, 0.28-0.85, \mathrm{p}=0.011 *)$. Further those in the urban were $53 \%$ less likely to engage in aPNS compared to those in the rural ( $\mathrm{OR}=0.47$; $\left.95 \% \mathrm{CI}, 0.28-0.78, \mathrm{p}=0.004^{*}\right)$.

The multivariate analysis showed that who were employed were $44 \%$ less likely to participate in aPNS compared to those who were self-employed ( $\mathrm{aOR}=0.56 ; 95 \% \mathrm{CI}, 0.33-0.95, \mathrm{p}=0.032$ ). Moreover, those who were peasants were more likely to participate in aPNS compare to those who were self-employed $(\mathrm{aOR}=2.04 ; 95 \% \mathrm{CI}, 1.08-3.85, \mathrm{p}=0.029)$. Finding also indicate that those who were residing in the urban setting were $43 \%$ less likely to participated in aPNS $(\mathrm{aOR}=0.57 ; 95 \% \mathrm{CI}, 0.33-0.98, \mathrm{p}=0.042)$.

\section{Discussion.}

For our study, we were able to achieve a participation rate of $69.1 \%$ among the adults on HIV care. The proportion was that a similar to a study carried out in the Tanzania(Plotkin et al., 2018) on the study on the outcomes of men and women on partner notification indicated that $63.4 \%$ of the male partners were successfully referred and $49.8 \%$ of the female partners were referred. However, the participation rates were low compared to a study in Mozambique where uptake of assisted partner notification was $85 \%$ where the index patients gave community health workers permission to contact their partners(Myers et al., 2016).Similarly, according a study in Tanzania on outcomes and factors associated with partner notification, 85\% of the HIV care clients consented to participate in partner notification(Lyamuya et al., 2020). Assisted partner notification was established to be safe, acceptable and effective(Myers et al., 2016). Awareness on the need of partner notification in order to reduce the HIV incidence and improve linkage to care for new infections might have also contributed to these participation rates. Several studies have demonstrated the benefits of offering HIV testing services the partners of people diagnosed 
with HIV (Brown et al., 2011; Cherutich et al., 2017; Rosenberg et al., 2015). The WHO also recommended the incorporation of partner notification in HIV testing.

We established that those residing in the rural areas were more likely to participate in aPNS similar to a study on index participant's characteristics which established high efficacy of aPNS in the rural areas (Masyuko et al., 2019). This can be explained by the low testing rates and access to testing sites in the rural settings(Mwangi et al., 2014). Therefore, due to low testing rates, participation in the aPNS in the rural settings is higher because of the need to test. Similarly, according to (Ng'ang'a et al., 2014) urban residents were more likely to have been tested compared to the rural residents. Therefore those who reside in the rural settings view aPNS to provide testing to their partners especially after HIV diagnosis due to the low uptake of testing in the setting.

Findings also indicated that those who were employed were less likely to participate in the aPNS. This concurs with findings in Uganda indicated that participation of the employed in the partner notification was low(Kahabuka et al., 2017). This can be explained by unavailability of those who were employed. Those who are employed are more likely to delay or forgo necessary health care provision.(Reichard et al., 2019). Although studies have shown that HIV testing is associated with employment(Frimpong et al., 2015; Hensen et al., 2015). Further, a study on women attending antenatal care established that women who were unemployed were more likely to undergo HIV testing(Thierman et al., 2006). Employment leads to increase the income status of an individual. According a common wealth report on health status and income, low income people are more likely to have poorer self-reported health and greater health risks, to have more mental health problems and have greater social needs or concerns. They are more fearful and less trusting of people in their neighbourhoods and have limited access to care (Peter J. Cunningham, 2018). Therefore this explains the increase in participation among those who were peasants and this is due to need basis. Moreover, lack of education and distrust of health care providers also limit the health seeking behaviour of low income earners(Lazar \& Davenport, 2018).

\section{Conclusion.}

This study documents low participation in assisted partner notification compared to other study findings although the uptake realised can be explained by the acceptability of the strategy and increased awareness in the need for HIV testing. These findings recommends the need to target 
additional interventions focused on reaching urban areas and work places on HIV testing as well expedite the importance of aPNS. Based on the limitations of self-reports, we also recommend future research on the determinants of aPNS in the country following its incorporation in the guidelines for HIV testing country wide in order to improve scale up of the program.

\section{Acknowledgment.}

Jomo Kenyatta University of Agriculture and Technology, Jaramogi Oginga Odinga Teaching and Referral Hospital (JOOTRH) ERC/IRB, County Government of Kisumu- Ministry of Health; County Director of Health, County Director of Education, County commissioner, Seme and Kisumu Sub Counties Sub County Health Management Teams, Health Management Teams Kombewa County Hospital, Chulaimbo County Hospital and Manyuanda Sub County Hospital.

\section{References.}

Brown, L. B., Miller, W. C., Kamanga, G., Nyirenda, N., Mmodzi, P., Pettifor, A., Dominik, R. C., Kaufman, J. S., Mapanje, C., Martinson, F., Cohen, M. S., \& Hoffman, I. F. (2011). HIV partner notification is effective and feasible in sub-Saharan Africa: Opportunities for HIV treatment and prevention. Journal of Acquired Immune Deficiency Syndromes (1999), 56(5), 437-442.

Cherutich, P., Golden, M. R., Wamuti, B., Richardson, B. A., Ásbjörnsdóttir, K. H., Otieno, F. A., Ng'ang'a, A., Mutiti, P. M., Macharia, P., Sambai, B., Dunbar, M., Bukusi, D., \& Farquhar, C. (2017). Assisted partner services for HIV in Kenya: a cluster randomised controlled trial. The Lancet HIV, 4(2), e74-e82. https://doi.org/10.1016/S2352-3018(16)30214-4

Dalal, S., Johnson, C., Fonner, V., Kennedy, C. E., Siegfried, N., Figueroa, C., \& Baggaley, R. (2017). Improving HIV test uptake and case finding with assisted partner notification services. AIDS (London, England), 31(13), 1867-1876. https://doi.org/10.1097/QAD.0000000000001555

Frimpong, J. A., Guerrero, E. G., Kong, Y., \& Tsai, G. (2015). Correlates of HIV testing and receipt of test results in addiction health services in Los Angeles County. Substance Abuse Treatment, Prevention, and Policy, 10(1), 31. https://doi.org/10.1186/s13011-015-0026-1

Hensen, B., Lewis, J., Schaap, A., Tembo, M., Vera-Hernández, M., Mutale, W., Weiss, H., Hargreaves, J., Stringer, J., \& Ayles, H. (2015). Frequency of HIV-testing and factors associated with multiple lifetime HIV-testing among a rural population of Zambian men. BMC Public Health, 15. https://doi.org/10.1186/s12889-015-2259-3

Hogben, M., McNally, T., McPheeters, M., \& Hutchinson, A. B. (2007). The effectiveness of HIV partner counseling and referral services in increasing identification of HIV-positive individuals a systematic review. American Journal of Preventive Medicine, 33(2 Suppl), S89-100. https://doi.org/10.1016/j.amepre.2007.04.015

Hogben, M., McNally, T., McPheeters, M., Hutchinson, A. B., \& Services, T. F. on C. P. (2007). The effectiveness of HIV partner counseling and referral services in increasing identification of HIVpositive individuals: a systematic review. American Journal of Preventive Medicine, 33(2), S89S100.

Kahabuka, C., Plotkin, M., Christensen, A., Brown, C., Njozi, M., Kisendi, R., Maokola, W., Mlanga, E., Lemwayi, R., Curran, K., \& Wong, V. (2017). Addressing the First 90: A Highly Effective 
Partner Notification Approach Reaches Previously Undiagnosed Sexual Partners in Tanzania. AIDS and Behavior, 21(8), 2551-2560. https://doi.org/10.1007/s10461-017-1750-5

Lazar, M., \& Davenport, L. (2018). Barriers to health care access for low income families: a review of literature. Journal of Community Health Nursing, 35(1), 28-37.

Lyamuya, F. S., Muro, E. P., Manongi, R., Mushi, D., Kiwelu, I., Katzenstein, T., \& Theilgaard, Z. (2020). Outcomes of and factors associated with partner notification and HIV testing in Northeastern Tanzania.

Masyuko, S. J., Cherutich, P. K., Contesse, M. G., Maingi, P. M., Wamuti, B. M., Macharia, P. M., Bukusi, D. E., Otieno, F. A., Spiegel, H. M., Dunbar, M. D., Golden, M. R., Richardson, B. A., \& Farquhar, C. (2019). Index participant characteristics and HIV assisted partner services efficacy in Kenya: results of a cluster randomized trial. Journal of the International AIDS Society, 22(S3), e25305. https://doi.org/10.1002/jia2.25305

Mwangi, M., Kellogg, T. A., Dadabhai, S. S., Bunnell, R., Baltazar, G., Ngare, C., K'Opiyo, G., Mburu, M., \& Kim, A. A. (2014). Factors Associated with Uptake of HIV Test Results in a NationallyRepresentative Population-Based AIDS Indicator Survey. The Open AIDS Journal, 8(1), 7-16. https://doi.org/10.2174/1874613601408010007

Myers, R. S., Feldacker, C., Cesár, F., Paredes, Z., Augusto, G., Muluana, C., Citao, S., Mboa-Ferrao, C., Karajeanes, E., \& Golden, M. R. (2016). Acceptability and Effectiveness of Assisted Human Immunodeficiency Virus Partner Services in Mozambique: Results From a Pilot Program in a Public, Urban Clinic. Sexually Transmitted Diseases, 43(11), 690-695. https://doi.org/10.1097/OLQ.0000000000000529

Ng'ang'a, A., Waruiru, W., Ngare, C., Ssempijja, V., Gachuki, T., Njoroge, I., Oluoch, P., Kimanga, D. O., Maina, W. K., Mpazanje, R., \& Kim, A. A. (2014). The Status of HIV Testing and Counseling in Kenya: Results From a Nationally Representative Population-Based Survey. Journal of Acquired Immune Deficiency Syndromes (1999), 66(Suppl 1), S27-S36. https://doi.org/10.1097/QAI.0000000000000102

Peter J. Cunningham. (2018). Why Even Healthy Low-Income People Have Greater Health Risks Than Higher-Income People Commonwealth Fund. https://www.commonwealthfund.org/blog/2018/healthy-low-income-people-greater-health-risks

Plotkin, M., Kahabuka, C., Christensen, A., Ochola, D., Betron, M., Njozi, M., Maokola, W., Kisendy, R., Mlanga, E., Curran, K., Drake, M., Kessy, E., \& Wong, V. (2018). Outcomes and Experiences of Men and Women with Partner Notification for HIV Testing in Tanzania: Results from a Mixed Method Study. AIDS and Behavior, 22(1), 102-116. https://doi.org/10.1007/s10461-017-1936-x

Reichard, A., Stransky, M., Brucker, D., \& Houtenville, A. (2019). The relationship between employment and health and health care among working-age adults with and without disabilities in the United States. Disability and Rehabilitation, 41(19), 2299-2307. https://doi.org/10.1080/09638288.2018.1465131

Rosenberg, N. E., Mtande, T. K., Saidi, F., Stanley, C., Jere, E., Paile, L., Kumwenda, K., Mofolo, I., Ng'ambi, W., Miller, W. C., Hoffman, I., \& Hosseinipour, M. (2015). Recruiting male partners for couple HIV testing and counselling in Malawi's option B+ programme: an unblinded randomised controlled trial. The Lancet. HIV, 2(11), e483-491. https://doi.org/10.1016/S23523018(15)00182-4

Thierman, S., Chi, B. H., Levy, J. W., Sinkala, M., Goldenberg, R. L., \& Stringer, J. S. A. (2006). Individual-level predictors for HIV testing among antenatal attendees in Lusaka, Zambia. The 
American Journal of the Medical Sciences, 332(1), 13-17. https://doi.org/10.1097/00000441200607000-00003

UNAIDS.

(2014).

The

Gap

Report.

https://www.unaids.org/en/resources/documents/2014/20140716_UNAIDS_gap_report

UNAIDS. (2018). http://www.unaids.org/en/resources/documents/2018/unaids-data-2018

Varghese, B., Peterman, T. A., \& Holtgrave, D. R. (1999). Cost-effectiveness of counseling and testing and partner notification: a decision analysis. AIDS (London, England), 13(13), 1745-1751. https://doi.org/10.1097/00002030-199909100-00019 